\title{
Effects of Water Solutions on Extracting Green Tea Leaves
}

\author{
Wen-Ying Huang, Yu-Ru Lin, Ruei-Fen Ho, Ho-Yen Liu, and Yung-Sheng Lin \\ Department of Applied Cosmetology and Master Program of Cosmetic Science, Hungkuang University, Taichung, Taiwan
}

Correspondence should be addressed to Yung-Sheng Lin; linys@sunrise.hk.edu.tw

Received 5 May 2013; Accepted 27 June 2013

Academic Editors: A. García-Vela, D. Kopelevich, and I. E. Pavel

Copyright (C) 2013 Wen-Ying Huang et al. This is an open access article distributed under the Creative Commons Attribution License, which permits unrestricted use, distribution, and reproduction in any medium, provided the original work is properly cited.

\begin{abstract}
This study investigates the effects of water solutions on the antioxidant content of green tea leaf extracts. Green teas prepared with tap water and distilled water were compared with respect to four antioxidant assays: total phenol content, reducing power, DMPD assay, and trolox equivalent antioxidant capacity assay. The results indicate that green tea prepared with distilled water exhibits higher antioxidant activity than that made with tap water. The high performance liquid chromatography showed that major constituents of green tea were found in higher concentrations in tea made with distilled water than in that made with tap water. This could be due to less calcium fixation in leaves and small water clusters. Water solutions composed of less mineralisation are more effective in promoting the quality of green tea leaf extracts.
\end{abstract}

\section{Introduction}

Green tea is an infusion of the leaves of the Camellia sinensis plant, a member of the Theaceae family $[1,2]$. As a popular drink favoured by Asians, in particular Chinese, green tea has received much global attention for its promotion of human health. A number of studies have shown that green tea possesses a wide range of biological activities [3], including antioxidant activity [4-9], anti-inflammatory activity [10], antimutagenic as well as anticarcinogenic activities [1114], and neuroprotective effects [15]. The major functional constituents of green tea, catechins, account for $8-15 \%$ of the dry leaf weight [16].

A variety of catechins, which are members of the polyphenol family, are present in green tea leaves. The four most abundant green tea epicatechins are (-)epigallocatechin gallate (EGCG), (-)-epicatechin gallate (ECG), (-)-epigallocatechin (EGC), and (-)-epicatechin (EC). In addition, four minor catechins are found in green tea leaves, including catechin (C), catechin gallate (CG), gallocatechin (GC), and gallocatechin gallate (GCG) $[16,17]$. Catechins have been reported to possess strong antioxidant activity and are widely accepted as important antioxidants, which eliminate free radicals [6].

It is presumed that different tea-processing procedures and water components will result in different qualities of green tea [18-21]. Previous studies have demonstrated that the temperature [22-24], $\mathrm{pH}$ [25], organic solvent [26], pressure [27], soaking time [28], and elements of water [29, 30] affect the antioxidant activity of green tea. However, how the physics-based mechanism of the water solution affects tea extracts has rarely been discussed.

The aim of this study is to compare the effects of making green tea extracts with tap water versus distilled water on the antioxidant activities of the extracts. Comparisons are made using the results of four antioxidant activity assays and high performance liquid chromatography component analyses. Following the literature review, a possible physicsbased mechanism to describe our observations is discussed.

\section{Materials and Methods}

2.1. Chemicals and Reagents. The green tea leaves were from TenRen Tea Co., Ltd., Taipei, Taiwan. Gallic acid (GA), 2,2' azino-bis(3-ethylbenzothiazoline-6-sulphonic acid) (ABTS), GC, EC, EGC, and EGCG were obtained from Sigma (USA). $N, N$-Dimethyl-p-phenylenediamine dihydrochloride (DMPD) and iron (III) chloride were purchased from Riedelde Haen (Germany). Folin-Ciocalteu reagent was from Fluka (Germany). Methanol, acetonitrile, and acetic acid were purchased from Merck (Darmstadt, Germany). 
2.2. Processing of Green Tea. Instead of a brewing process $[7,31]$, green tea solutions were prepared using tap water and distilled water at $25^{\circ} \mathrm{C}$. The former was taken from the suburban area of the City of Greater Taichung, Taiwan. Distilled water $(<1 \mu \mathrm{S} / \mathrm{cm})$ was purified using a Millipore AlphaQ Luton ultrapure water system such that both the organic and inorganic impurities were removed. Two water samples were divided into $25 \mathrm{~mL}$ aliquots in $50 \mathrm{~mL}$ polypropylene centrifuge tubes. Aqueous extracts were prepared by soaking a $31.25 \mathrm{mg}$ infusion of ground up and homogenized dry green tea leaves in $25 \mathrm{~mL}$ water at $25^{\circ} \mathrm{C}$ for $20 \mathrm{~min}$. After centrifugation $(1250 \mathrm{rpm})$, the green tea supernatant was collected for further examination; five replicates were made for statistical analysis.

2.3. Total Phenol Content. The total phenol content of green tea was measured according to Gutfinger's method [32]. Each green tea solution was mixed with $250 \mu \mathrm{L}$ Folin-Ciocalteu reagent for $1 \mathrm{~min}$ and $50 \mu \mathrm{L} 2 \% \mathrm{Na}_{2} \mathrm{CO}_{3}$ for $5 \mathrm{~min}$. The absorbance at $655 \mathrm{~nm}$ (Sunrise ELISA Plate Reader, Tecan, Austria) denoted the total phenol content, and it increased with the content of phenols.

2.4. Reducing Power. As described in a previous report [33], the reducing power of green tea was determined using a mixture of $250 \mu \mathrm{L}$ phosphate buffer (200 mM, pH 6.6), $250 \mu \mathrm{L}$ potassium ferricyanide ( $1 \%$ by weight), and $500 \mu \mathrm{L}$ green tea. The mixture was then incubated at $50^{\circ} \mathrm{C}$ for $20 \mathrm{~min}$. Trichloroacetic acid ( $250 \mu \mathrm{L}, 10 \%$ by weight $)$ was mixed with distilled water $(250 \mu \mathrm{L})$ and $\mathrm{FeCl}_{3}(750 \mu \mathrm{L}, 0.1 \%$ by weight), allowed to react for $30 \mathrm{~min}$, and the absorbance at $700 \mathrm{~nm}$ was measured using a spectrophotometer. Higher absorbance indicated greater reducing power.

2.5. DMPD Assay. Antioxidant activities of green tea were measured according to Schlesier's method [34]. In principle, colorless DMPD will form a stable purple free radical cation, $\mathrm{DMPD}^{+} \bullet$, in the presence of a suitable oxidant, such as $\mathrm{FeCl}_{3}$. Purple $\mathrm{DMPD}^{+} \bullet$ is scavenged and decolorized upon addition of an antioxidant. Equal volumes of $24 \mathrm{mM}$ DMPD, $2.4 \mathrm{mM}$ $\mathrm{FeCl}_{3}$, and $0.6 \mathrm{M}$ acetic acid were mixed together for $5 \mathrm{~min}$ to generate $\mathrm{DMPD}^{+} \bullet$, and the absorbance at $495 \mathrm{~nm}$ was measured. The antioxidant activity was inferred as the ability to scavenge free radicals, and a decrease in absorbance was inferred as increasing scavenging power, defined as follows:

$$
\begin{gathered}
\mathrm{DMPD}^{+} \cdot \text { scavenging activity (\%) } \\
=\left[1-\left(\frac{\mathrm{A} 2}{\mathrm{~A} 1}\right)\right] \times 100 \%,
\end{gathered}
$$

where A1 denotes the absorbance of total free $\mathrm{DMPD}^{+}$. radicals and $\mathrm{A} 2$ denotes the absorbance following addition of the antioxidant.

2.6. Trolox Equivalent Antioxidant Capacity Assay. The trolox equivalent antioxidant capacity (TEAC) assay was carried out using the procedure described by Erkan's method [35]. In brief, $\mathrm{ABTS}^{+} \cdot$ was produced by reacting $7 \mathrm{mM}$ ABTS with
$2.45 \mathrm{mM}$ potassium persulfate in the dark at $4^{\circ} \mathrm{C}$ for $12 \mathrm{~h}$. A $30 \mu \mathrm{L}$ antioxidant aliquot was added to $2 \mathrm{~mL} \mathrm{ABTS}^{+} \cdot$ radical solution, allowed to react for $10 \mathrm{~min}$, and the absorbance measured at $734 \mathrm{~nm}$.

As stated previously, the antioxidant capacity was inferred as the ability to scavenge free radicals, expressed as follows:

$$
\begin{gathered}
\mathrm{ABTS}^{+} \cdot \text { scavenging activity (\%) } \\
=\left[1-\left(\frac{\mathrm{A} 4}{\mathrm{~A} 3}\right)\right] \times 100 \%,
\end{gathered}
$$

where A3 represents the absorbance of total free $\mathrm{ABTS}^{+}$. radicals, and $\mathrm{A} 4$ represents the absorbance following addition of the antioxidant.

2.7. High Performance Liquid Chromatography. The extract of green tea was mixed with an internal standard solution ( $0.5 \mathrm{mg}$ gallic acid diluted to $25 \mathrm{~mL}$ with $70 \%$ methanol) at a ratio of $1: 1$. The samples were spiked with various concentrations of stock solutions and then analyzed.

A stock solution was prepared by dissolving four marker substances (GC, $1.0 \mathrm{mg}$; EGC, $5.0 \mathrm{mg}$; EGCG, $2.5 \mathrm{mg}$; and EC, $10.0 \mathrm{mg}$ ) in $1 \mathrm{~mL}$ of $70 \%$ methanol; the solution was then stored in a refrigerator. Stock solutions were diluted with $70 \%$ methanol into a series of standard solutions (GC: 0.78, $1.04,1.25,1.56,2.08$, and $3.13 \mu \mathrm{g} / \mathrm{mL}$; EGC: $2.50,6.25,7.81$, 10.41, 15.63, and 31.25 $\mu \mathrm{g} / \mathrm{mL}$; EGCG: 2.60, 3.13, 3.91, 5.21, and $7.81 \mu \mathrm{g} / \mathrm{mL}$; EC: $2.08,4.17,4.63,5,6.25$, and $8.33 \mu \mathrm{g} / \mathrm{mL})$. A $20 \mu \mathrm{L}$ aliquot of each solution was injected and analyzed two times using HPLC, and the standard curves were plotted as peak areas versus concentrations. Recovery was determined by comparing the amount of marker substances added to the marker substances found. The limits of detection were based on a signal to noise $(\mathrm{S} / \mathrm{N})$ ratio of $3: 1$ as a minimum.

HPLC was performed on an Agilent 1220 series system. Satisfactory separation of the markers was obtained using a reversed-phase column (Cosmosil 5C18-AR II, $5 \mu \mathrm{m}, 25 \mathrm{~cm} \times$ $4.6 \mathrm{~mm}$ I.D., Nacalai Tesque, Kyoto, Japan) at $280 \mathrm{~nm}$, an elution flow rate of $0.8 \mathrm{~mL} / \mathrm{min}$, and a linear solvent gradient of A-B (A, $10 \mathrm{mM} \mathrm{KH}_{2} \mathrm{PO}_{4}(\mathrm{pH} 4.0) ; \mathrm{B}, \mathrm{CH}_{3} \mathrm{CN}, \mathrm{CH}_{3} \mathrm{OH}$, and $\mathrm{H}_{2} \mathrm{O}$ at a ratio of 1.5:2.5: 1, respectively, $\left.[\mathrm{v} / \mathrm{v} / \mathrm{v}]\right)$ as follows: $0 \mathrm{~min}, 20 \% \mathrm{~B}$; $5 \mathrm{~min}, 20 \% \mathrm{~B}$; $15 \mathrm{~min}, 30 \% \mathrm{~B}$; $45 \mathrm{~min}$, $60 \% \mathrm{~B}$.

2.8. Statistical Analysis. The paired $t$-test method was used to evaluate differences between groups. A value of $P<0.05$ was considered statistically significant $\left({ }^{*}\right)$, and $P<0.01$ was highly significant $\left({ }^{* *}\right)$.

\section{Results and Discussion}

3.1. Total Phenol Content. Figure 1 shows the differences in $\mathrm{A}_{655}$ between the tea solutions. Indicating the total amount of phenol, the $\mathrm{A}_{655}$ for the control (no green tea extract), green tea made with distilled water, and green tea made with tap water were $0.06 \pm 0.02,0.81 \pm 0.03$, and $0.69 \pm 0.03$, respectively. Phenols are regarded as significant constituents of green tea because of their free-radical scavenging ability. 


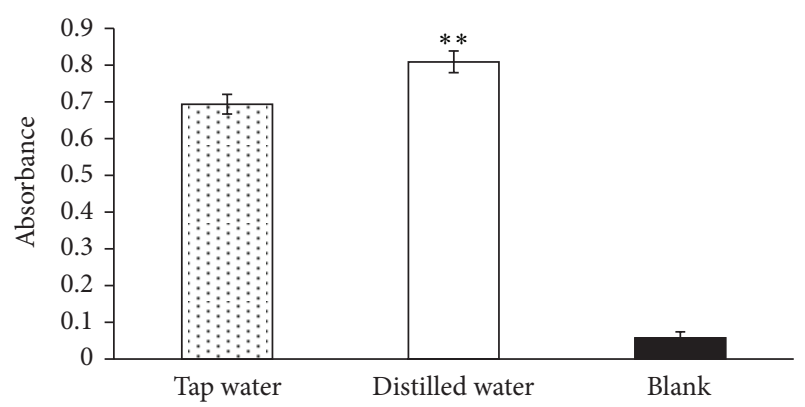

Figure 1: Effects of water solution on the total phenol content of green tea.

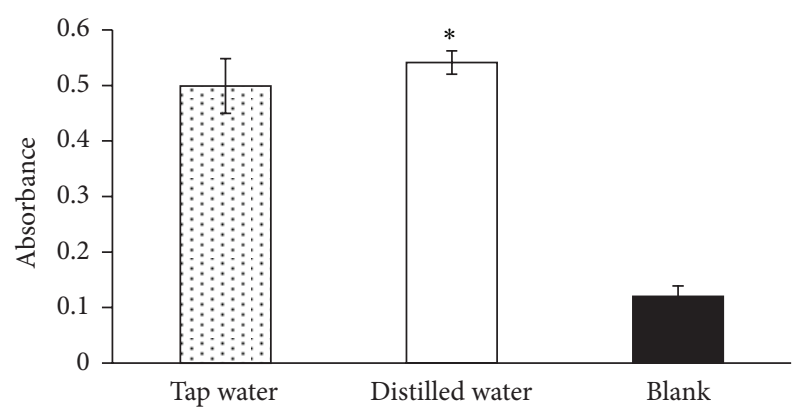

FIGURE 2: Effects of water solution on the reducing power of green tea.

3.2. Reducing Power. The reducing power of a compound serves as an indicator of its antioxidant activity [33]. Figure 2 shows the reducing power (absorbance at $700 \mathrm{~nm}$ ) of the 3 groups tested. The $A_{700}$ for the control, green tea made with distilled water, and green tea made with tap water were $0.11 \pm 0.02,0.53 \pm 0.03$, and $0.47 \pm 0.06$, respectively.

3.3. DMPD Assay. Figure 3 shows that the inhibition of $\mathrm{DMPD}^{+} \bullet$ radical cations by green tea was $84.04 \pm 3.10 \%$ when made with distilled water and $82.15 \pm 2.46 \%$ when made with tap water. Compared to tea made with tap water, there was a $1.89 \%$ improvement in $\mathrm{DMPD}^{+} \cdot$ scavenging activity in the tea made with distilled water. Thus, the distilled water was able to extract more antioxidant substances from the green tea leaves as determined by $\mathrm{DMPD}^{+} \cdot$ scavenging activity.

3.4. Trolox Equivalent Antioxidant Capacity Assay. Figure 4 indicates that $\mathrm{ABTS}^{+}$- radicals were inhibited by $78.75 \pm$ $1.81 \%$ and $71.01 \pm 1.41 \%$ in green tea made using distilled water and tap water, respectively. Results of the TEAC assay demonstrate that green tea made with distilled water has superior $\mathrm{ABTS}^{+}$- scavenging activity (7.74\% increase) compared to green tea made with tap water. These results suggest that distilled water has a clear advantage over tap water in terms of its ability to extract more antioxidants into the tea solution.

3.5. High Performance Liquid Chromatography. Calibration curves were prepared by plotting the peak-area ratios (using

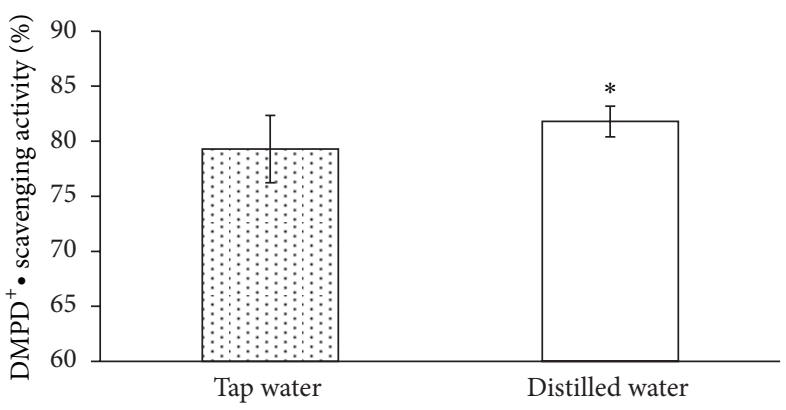

FIGURE 3: Effects of water solution on $\mathrm{DMPD}^{+} \bullet$ scavenging activity in green tea.

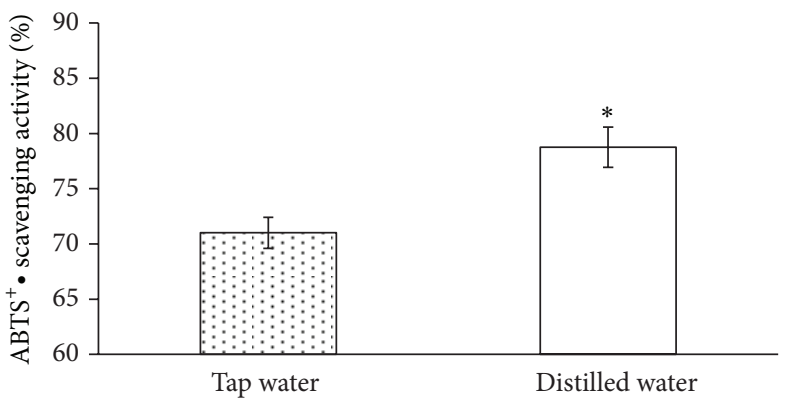

FIGURE 4: Effects of water solutions on $\mathrm{ABTS}^{+} \bullet$ scavenging activity in green tea.

gallic acid as an internal standard) against the corresponding concentrations. Using linear regression to analyze data in the concentration range of interest, the detection limits were between 0.078 and $1.25 \mu \mathrm{g} / \mathrm{mL}(\mathrm{S} / \mathrm{N}=3)$ for the components.

By substituting the peak-area ratios of individual peaks acquired using HPLC, the contents of individual components in the green tea were determined. The average amounts of 4 constituents in teas made using tap water and distilled water, respectively, were $(\mathrm{mg} / \mathrm{g} \pm \mathrm{SD})$ : GC, $4.43 \pm 0.94$ and $3.35 \pm$ 0.53 ; EGC, $5.86 \pm 1.78$ and $21.03 \pm 0.47$; EGCG, $1.43 \pm 0.07$ and $12.36 \pm 0.03$; EC, $5.52 \pm 0.21$ and $10.26 \pm 0.18$. Of these 4 constituents, EGC, EGCG, and EC show higher amounts in the distilled water sample than its tap water counterpart, as shown in Figure 5.

3.6. Ion Concentration. The extraction efficiency of green tea leaves depends on the presence of electrolytes. Therefore, the ions present in water were further determined by the inductively coupled plasma mass spectrometry (SCIEX Elan 5000, Perkin Elmer, Überlingen, Germany). Table 1 shows the cation contents in two waters of this study. There is a higher cation concentration in tap water than distilled water. Corresponding to previous reports [36], the higher the mineralisation, the lower the green tea leaves extraction yields of organic matter. The reason may be also attributed to that calcium is taken up by leaves from highly mineralised water and assumed to be complexed with pectins in cell walls. The formation of complex will retard extraction of green tea leaves thus explaining the decrease in extraction yield. 


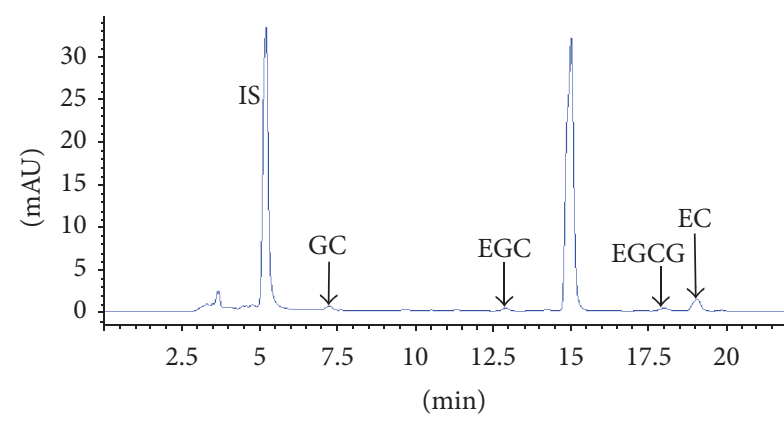

(a)

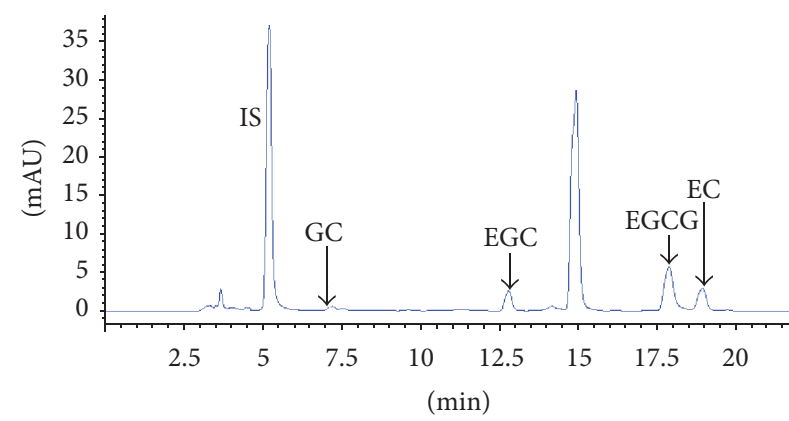

(b)

FIGURE 5: High performance liquid chromatography spectra of green tea prepared with different water solutions. (a) Tap water and (b) distilled water $(\mathrm{IS}=$ gallic acid, GC $=$ gallocatechin, EGC $=(-)$-epigallocatechin, EGCG $=(-)$-epigallocatechin gallate, and EC = $(-)$-epicatechin) .

TABLE 1: Cation compositions of tap water and distilled water.

\begin{tabular}{lccccc}
\hline \multirow{2}{*}{ Water } & \multicolumn{5}{c}{ Cation concentration (ppb) } \\
& $\mathrm{Ca}^{2+}$ & $\mathrm{Al}^{3+}$ & $\mathrm{Na}^{+}$ & $\mathrm{Mg}^{2+}$ & $\mathrm{K}^{+}$ \\
\hline Tap water & 21690 & 13.33 & 10120 & 6698 & 1361 \\
Distilled water & 115.2 & 0.465 & 9.035 & 2.159 & 0.941 \\
\hline
\end{tabular}

Besides, tea polyphenols which are the leading functional component may combine with ions such as $\mathrm{Ca}^{2+}$ and $\mathrm{Mg}^{2+}$ to be partially retained in tea residue [37].

Except calcium fixation in leaves, the water structure may also affect extraction efficiency. Water structures have been studied for over 100 years in various research fields, including physics, chemistry, and physical chemistry [38]. Many theoretical and experimental approaches for studying the structure of water have been well developed (e.g., statistical thermodynamics, molecular dynamics simulation, infrared spectrum, Raman spectrum, X-ray diffraction, neutron diffraction, and NMR) [39-41]. Electrolytes have been shown to affect the median number of water clusters and the cluster size $[39,42]$. This observation supports the idea that water organized into smaller clusters can extract more functional constituents of green tea leaves and hence enhances the antioxidant activity of green tea. The ratedetermining step in tea leaf infusion was determined to be the diffusion of solutes through the leaf matrix to the surface [43]. Smaller water clusters provide larger surface areas, thus increasing contact opportunities between water molecules and green tea leaves and allowing the extraction of more solutes from the leaves. In addition, the interaction between the sample and the extracting solvent is enhanced due to the increased number of water clusters, resulting in a highly efficient extraction. In this study, cations increase the median water cluster size [39] and decrease extraction of green tea leaves.

\section{Conclusions}

This study investigated the effects of water conditions on the efficiency of constituent extraction from green tea leaves. The increase in polyphenol extraction in green tea prepared with distilled water increases its antioxidant activity. Our results revealed that distilled water may be a good choice for extracting compounds probably due to its less calcium fixation in leaves and smaller water cluster size, thus enhancing the antioxidant activity of green tea made with distilled water. These results provide an alternative application of distilled water in the processing of certain foods.

\section{Conflict of Interests}

The authors declare that they have no competing interests. All authors have no financial relation with the commercial identities mentioned in the paper.

\section{Acknowledgment}

The authors feel deeply indebted to the National Science Council, Taiwan, for all the resources gained under Grant no. NSC101-2622-E-241-002-CC3.

\section{References}

[1] M. D. Brown, "Green tea (Camellia sinensis) extract and its possible role in the prevention of cancer," Alternative Medicine Review, vol. 4, no. 5, pp. 360-370, 1999.

[2] J. V. Higdon and B. Frei, “Tea catechins and polyphenols: health effects, metabolism, and antioxidant functions," Critical Reviews in Food Science and Nutrition, vol. 43, pp. 89-143, 2003.

[3] A. B. Sharangi, "Medicinal and therapeutic potentialities of tea (Camellia sinensis L.) - a review," Food Research International, vol. 42, no. 5-6, pp. 529-535, 2009.

[4] S. M. Henning, Y. T. Niu, N. H. Lee et al., "Bioavailability and antioxidant activity of tea flavanols after consumption of green tea, black tea, or a green tea extract supplement," American Journal of Clinical Nutrition, vol. 80, no. 6, pp. 1558-1564, 2004.

[5] L. A. Beltz, D. K. Bayer, A. L. Moss, and I. M. Simet, "Mechanisms of cancer prevention by green and black tea polyphenols," Anti-Cancer Agents in Medicinal Chemistry, vol. 6, no. 5, pp. 389-406, 2006.

[6] N. P. Seeram, S. M. Henning, Y. Niu, R. Lee, H. S. Scheuller, and D. Heber, "Catechin and caffeine content of green tea dietary supplements and correlation with antioxidant capacity," Journal 
of Agricultural and Food Chemistry, vol. 54, no. 5, pp. 1599-1603, 2006.

[7] S.-D. Lin, E.-H. Liu, and J.-L. Mau, "Effect of different brewing methods on antioxidant properties of steaming green tea," LWT_Food Science and Technology, vol. 41, no. 9, pp. 1616-1623, 2008.

[8] M. Bancirova, "Comparison of the antioxidant capacity and the antimicrobial activity of black and green tea," Food Research International, vol. 43, no. 5, pp. 1379-1382, 2010.

[9] A. S. G. Costa, M. A. Nunes, I. M. C. Almeida et al., "Teas, dietary supplements and fruit juices: a comparative study regarding antioxidant activity and bioactive compounds," LWT_Food Science and Technology, vol. 49, pp. 324-328, 2012.

[10] H. Cao, M. A. Kelly, F. Kari et al., "Green tea increases antiinflammatory tristetraprolin and decreases pro-inflammatory tumor necrosis factor mRNA levels in rats," Journal of Inflammation, vol. 4, article 1, 2007.

[11] J. Khatiwada, M. Verghese, L. T. Walker, L. Shackelford, C. B. Chawan, and R. Sunkara, "Combination of green tea, phytic acid, and inositol reduced the incidence of azoxymethaneinduced colon tumors in Fisher 344 male rats," LWT-Food Science and Technology, vol. 39, no. 10, pp. 1080-1086, 2006.

[12] J. D. van der Merwe, E. Joubert, E. S. Richards et al., "A comparative study on the antimutagenic properties of aqueous extracts of Aspalathus linearis (rooibos), different Cyclopia spp. (honeybush) and Camellia sinensis teas," Mutation Research, vol. 611, no. 1-2, pp. 42-53, 2006.

[13] C. S. Yang, S. Sang, J. D. Lambert, Z. Hou, J. Ju, and G. Lu, "Possible mechanisms of the cancer-preventive activities of green tea," Molecular Nutrition \& Food Research, vol. 50, pp. 170-175, 2006.

[14] H.-S. Jeong, S. Jang, M.-J. Jang et al., "Effects of (-)-epigallocatechin-3-gallate on the activity of substantia nigra dopaminergic neurons," Brain Research, vol. 1130, no. 1, pp. 114-118, 2007.

[15] S. Mandel, O. Weinreb, T. Amit, and M. B. H. Youdim, "Cell signaling pathways in the neuroprotective actions of the green tea polyphenol (-)-epigallocatechin-3-gallate: implications for neurodegenerative diseases," Journal of Neurochemistry, vol. 88, no. 6, pp. 1555-1569, 2004.

[16] Y. Yoshida, M. Kiso, and T. Goto, "Efficiency of the extraction of catechins from green tea," Food Chemistry, vol. 67, no. 4, pp. 429-433, 1999.

[17] S. C. Lee, S. Y. Kim, S. M. Jeong, and J. H. Park, "Effect of farinfrared irradiation on catechins and nitrite scavenging activity of green tea," Journal of Agricultural and Food Chemistry, vol. 54, pp. 399-403, 2006.

[18] Y. Huang, J. Sheng, F. Yang, and Q. Hu, "Effect of enzyme inactivation by microwave and oven heating on preservation quality of green tea," Journal of Food Engineering, vol. 78, no. 2, pp. 687-692, 2007.

[19] V. R. Sinija, H. N. Mishra, and S. Bal, "Process technology for production of soluble tea powder," Journal of Food Engineering, vol. 82, no. 3, pp. 276-283, 2007.

[20] D. Komes, D. Horžić, A. Belščak, K. K. Ganić, and I. Vulić, "Green tea preparation and its influence on the content of bioactive compounds," Food Research International, vol. 43, pp. 167-176, 2010.

[21] J. Hu, Y. Chen, and D. Ni, "Effect of superfine grinding on quality and antioxidant property of fine green tea powders," LWT-Food Science and Technology, vol. 45, pp. 8-12, 2012.
[22] J. Xi, D. Shen, S. Zhao, B. Lu, Y. Li, and R. Zhang, "Characterization of polyphenols from green tea leaves using a high hydrostatic pressure extraction," International Journal of Pharmaceutics, vol. 382, pp. 139-143, 2009.

[23] M. von Staszewski, A. M. R. Pilosof, and R. J. Jagus, "Antioxidant and antimicrobial performance of different Argentinean green tea varieties as affected by whey proteins," Food Chemistry, vol. 125, no. 1, pp. 186-192, 2011.

[24] X. Jun, S. Deji, L. Ye, and Z. Rui, "Comparison of in vitro antioxidant activities and bioactive components of green tea extracts by different extraction methods," International Journal of Pharmaceutics, vol. 408, pp. 97-101, 2011.

[25] B. F. Zimmermann and M. Gleichenhagen, "The effect of ascorbic acid, citric acid and low $\mathrm{pH}$ on the extraction of green tea: how to get most out of it," Food Chemistry, vol. 124, no. 4, pp. 1543-1548, 2011.

[26] F. Li, F. Wang, F. Yu et al., "In vitro antioxidant and anticancer activities of ethanolic extract of selenium-enriched green tea," Food Chemistry, vol. 111, no. 1, pp. 165-170, 2008.

[27] J. Xi, D. Shen, Y. Li, and R. Zhang, "Ultrahigh pressure extraction as a tool to improve the antioxidant activities of green tea extracts," Food Research International, vol. 44, pp. 2783-2787, 2011.

[28] Q. V. Vuong, C. E. Stathopoulos, J. B. Golding, M. H. Nguyen, and P. D. Roach, "Optimum conditions for the water extraction of L -theanine from green tea," Journal of Separation Science, vol. 34, no. 18, pp. 2468-2474, 2011.

[29] D. R. Zhou, Y. Q. Chen, and D. J. Ni, "Effect of water quality on the nutritional components and antioxidant activity of green tea extracts," Food Chemistry, vol. 113, pp. 110-114, 2009.

[30] M. S. Bae and S. C. Lee, "Effect of deep sea water on the antioxidant activity and catechin content of green tea," Journal of Medicinal Plants Research, vol. 4, no. 16, pp. 1662-1667, 2010.

[31] S.-D. Lin, C.-H. Liang, E.-H. Liu, and J.-L. Mau, "Antioxidant properties of water extracts from parching green tea," Journal of Food Biochemistry, vol. 34, no. 3, pp. 477-500, 2010.

[32] T. Gutfinger, "Polyphenols in olive oils," Journal of the American Oil Chemists Society, vol. 58, no. 11, pp. 966-968, 1981.

[33] Y.-S. Shyu, J.-T. Lin, Y.-T. Chang, C.-J. Chiang, and D.-J. Yang, "Evaluation of antioxidant ability of ethanolic extract from dill (Anethum graveolens L.) flower," Food Chemistry, vol. 115, no. 2, pp. 515-521, 2009.

[34] K. Schlesier, M. Harwat, V. Böhm, and R. Bitsch, "Assessment of antioxidant activity by using different in vitro methods," Free Radical Research, vol. 36, no. 2, pp. 177-187, 2002.

[35] N. Erkan, G. Ayranci, and E. Ayranci, "Antioxidant activities of rosemary (Rosmarinus Officinalis L.) extract, blackseed (Nigella sativa L.) essential oil, carnosic acid, rosmarinic acid and sesamol," Food Chemistry, vol. 110, no. 1, pp. 76-82, 2008.

[36] A. Mossion, M. Potin-Gautier, S. Delerue, I. Le Hécho, and P. Behra, "Effect of water composition on aluminium, calcium and organic carbon extraction in tea infusions," Food Chemistry, vol. 106, no. 4, pp. 1467-1475, 2008.

[37] D. Zhou, Y. Chen, and D. Ni, "Effect of water quality on the nutritional components and antioxidant activity of green tea extracts," Food Chemistry, vol. 113, pp. 110-114, 2009.

[38] F. H. Stillinger, "Water revisited," Science, vol. 209, no. 4455, pp. 451-457, 1980.

[39] R. Li, Z. Jiang, H. Yang, and Y. J. Guan, "Effects of ions in natural water on the ${ }^{17} \mathrm{O}$ NMR chemical shift of water and their relationship to water cluster," Journal of Molecular Liquids, vol. 126, pp. 14-18, 2006. 
[40] S. J. Suresh, K. Kapoor, S. Talwar, and A. Rastogi, "Internal structure of water around cations," Journal of Molecular Liquids, vol. 174, pp. 135-142, 2012.

[41] S. Shimokawa, T. Yokono, T. Mizuno, H. Tamura, T. Erata, and T. Araiso, "Effect of far-infrared light irradiation on water as observed by X-ray diffraction measurements," Japanese Journal of Applied Physics 2, vol. 43, no. 4, pp. L545-L547, 2004.

[42] G. Markovich, S. Pollack, R. Giniger, and O. Cheshnovsky, "Photoelectron spectroscopy of Cl-, Br-, and I - solvated in water clusters," The Journal of Chemical Physics, vol. 101, no. 11, pp. 9344-9353, 1994.

[43] C. Astill, M. R. Birch, C. Dacombe, P. G. Humphrey, and P. T. Martin, "Factors affecting the caffeine and polyphenol contents of black and green tea infusions," Journal of Agricultural and Food Chemistry, vol. 49, no. 11, pp. 5340-5347, 2001. 

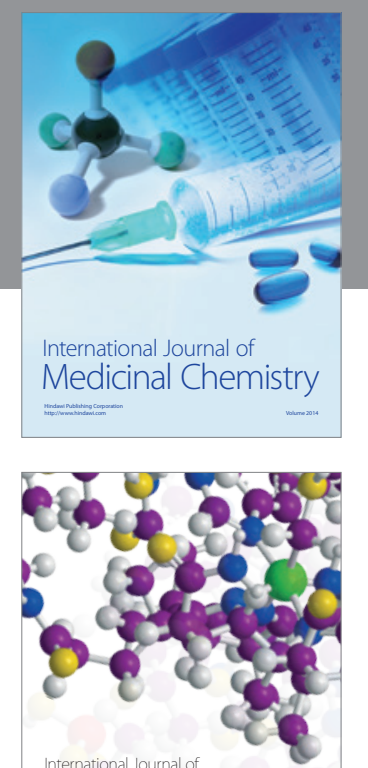

\section{Carbohydrate} Chemistry

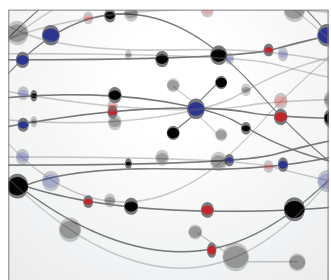

The Scientific World Journal
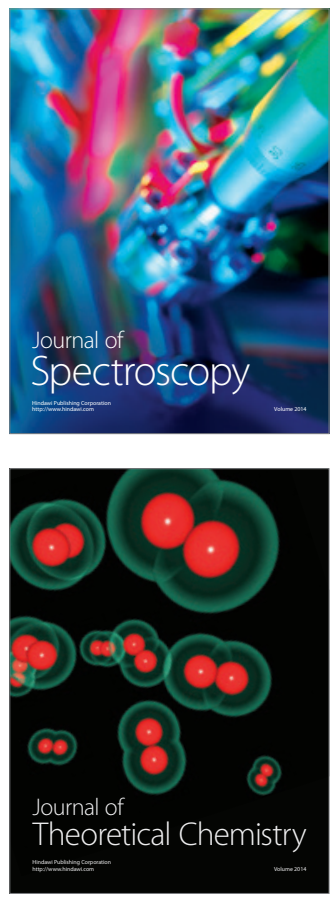
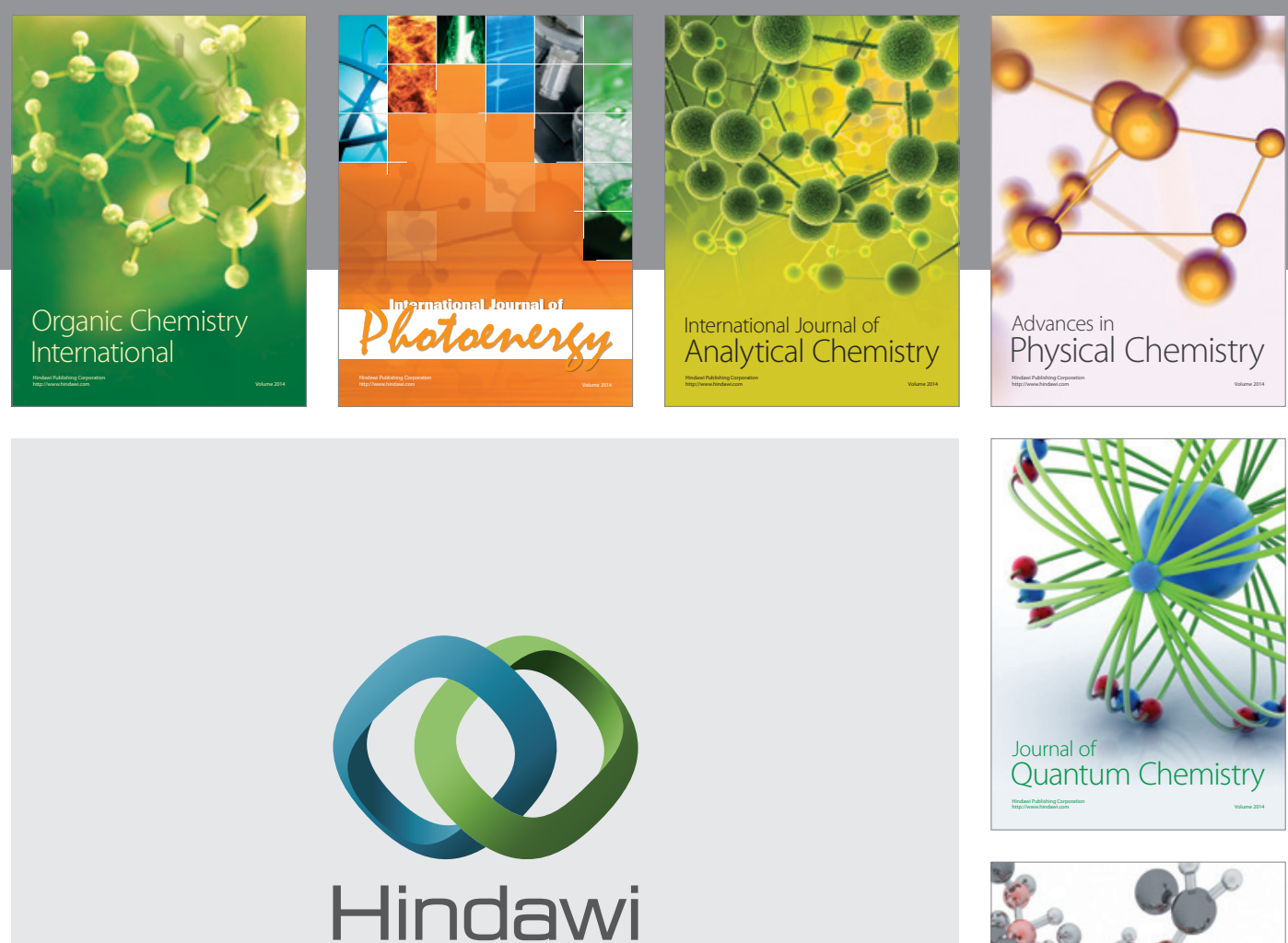

Submit your manuscripts at

http://www.hindawi.com

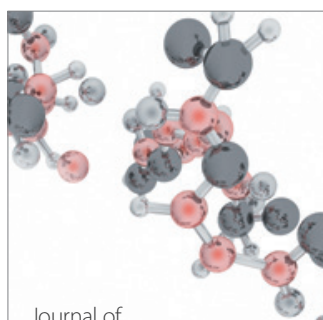

Analytical Methods

in Chemistry

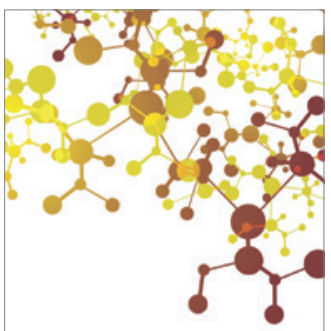

Journal of

Applied Chemistry

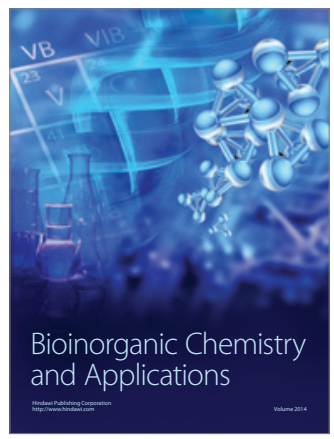

Inorganic Chemistry
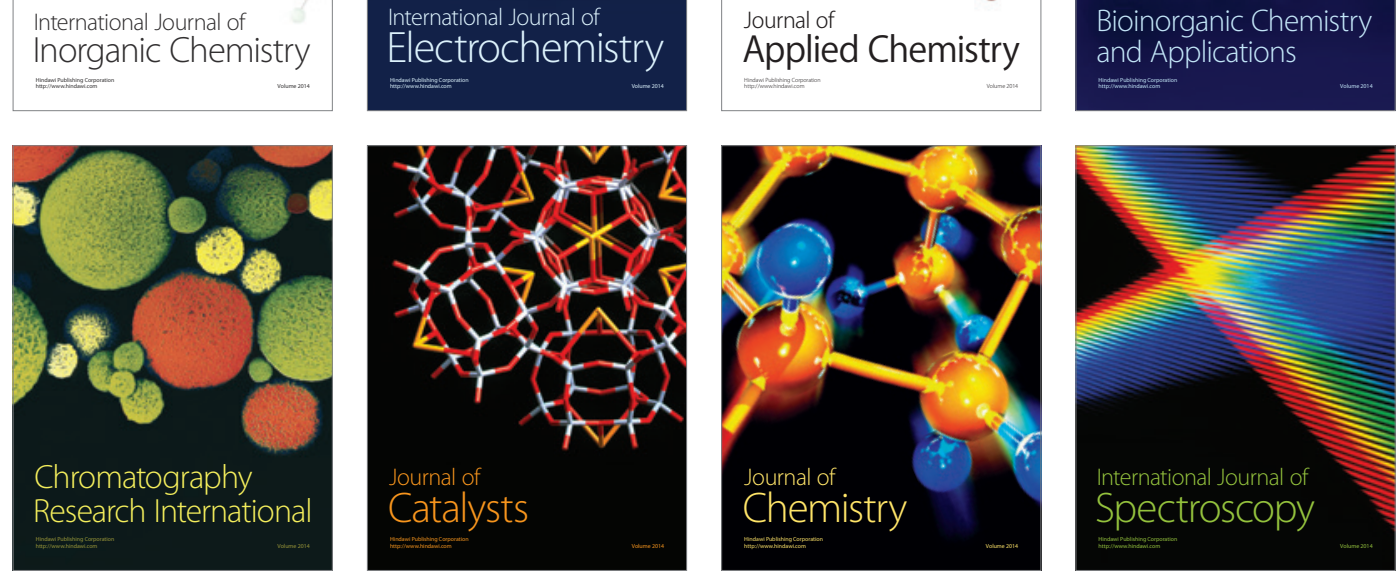